\title{
Professional Characteristics of Health Promotion: A Scoping Review of the German and International Literature
}

\author{
Verena Biehl ${ }^{1,2 *}$, Thomas Gerlinger ${ }^{2}$ and Frank Wieber ${ }^{1,3}$ \\ ${ }^{1}$ School of Health Professions, Institute of Health Sciences, Zurich University of Applied Sciences, Winterthur, Switzerland, \\ ${ }^{2}$ Department of Health Care Systems, Health Policy and Sociology of Health, Faculty of Health Sciences, University of Bielefeld, \\ Bielefeld, Germany, ${ }^{3}$ Department of Psychology, University of Konstanz, Konstanz, Germany
}

Objective: This scoping review investigates current developments in the professional characteristics of health promotion (HP) with a focus on the German speaking part of Europe. The conceptualization of $\mathrm{HP}$ is a prerequisite for progressing HP professionalization and clarifying the interconnectedness between HP and Public Health.

Methods: The search strategy was informed by sociological professionalization theories. Original publications were included in a content-based analysis.

Results: Ninety publications (37 original publications) were identified in the review. The results are summarized in categories based on professional characteristics: 1) profession, 2) ethics, 3) education/training 4) competencies, and 5) quality. The professionalization of $\mathrm{HP}$ regarding the professional characteristics is less developed in the German compared to the international literature.

OPEN ACCESS

Edited by:

Alberto Borraccino,

University of Turin, Italy

Reviewed by:

Dean Whitehead, University of Tasmania, Australia Helen Keleher,

Monash University, Australia

*Correspondence:

Verena Bieh

verena.biehl@zhaw.ch

Received: 24 January 2021 Accepted: 04 June 2021 Published: 01 July 2021

Citation:

Biehl V, Gerlinger $T$ and Wieber $F$ (2021) Professional Characteristics of Health Promotion: A Scoping Review

of the German and

International Literature. Int J Public Health 66:1603993.

doi: 10.3389/ijph.2021.1603993
Conclusion: The mixed findings emphasize the relevance of a common HP conceptualization. The HP core competencies, which have been developed by the International Union for Health Promotion and Education must be further promoted. A strong HP workforce within Public Health strengthens the HP status in policy contexts and society and its contribution to promoting health and tackling social inequalities in health.

Keywords: health promotion, public health, professionalization, professional characteristics, professional competencies

\section{INTRODUCTION}

In pursuing the overarching goal of preventing and managing health problems worldwide, health promotion (HP) offers valuable competencies that can contribute to political and societal efforts. With its focus on socioenvironmental determinants of health at a community level as described in the Ottawa Charta in 1986, HP has the potential to promote health and well-being for all groups of society $[1,2]$. In line with this increasing recognition of the relevance of HP, the United Nations explicitly referred to it in the Sustainable Development Goals for 2030 in goal 3: "Enable healthy lives and promote well-being for all at all ages" [3]. These goals are particularly important given that individualism, urbanization and globalization are driving many major contemporary health issues, including noncommunicable diseases, and call for rethinking our health systems with a strengthened focus on HP and prevention that complements the traditional focus on disease management and health care $[4,5]$. However, the often suboptimal quality of HP practice [6-8] and the lack of Public 
Health $(\mathrm{PH})$ professionals $[9,10]$ call for a stronger HP workforce. Although HP has come a long way since the 1980s, it is not wellestablished as a profession in our society yet, at least in the German speaking part of Europe [11-15].

For better comprehensibility the following section provides descriptions for the central terms in this article and their relation between each other referring to Mieg, 2016 [16]. Professionalization in this article is understood as an overall term for the development of the field of action of HP being performed by professionals. Within the professionalization process a main requirement is the conceptualization of the concrete field of action, which can then be described by specific professional characteristics. As identification of professional characteristics therefore represents a central building block to support the development of the HP profession, this study aims to provide an overview of the professional characteristics of the HP profession described in the literature. Thereby, professional characteristics don't capture the analysis of a whole profession but facilitate the understanding of different relevant aspects of a single profession. We understand professional HP as it was conceptualized in the Ottawa Charta: a salutogenic perspective on health focusing on populations based on the principles of participation, empowerment and health equity. HP is a multilayered concept to initiate a paradigm shift within our health systems to a state of Health in all Policies [1]. This means many professions are involved in this paradigm shift including a specific profession - the HP practitioner.

Professionals are needed to face complex challenges in today's knowledge-oriented societies, such as the promotion of well-being and population health. As systematic approaches to describe professional characteristics, a variety of sociological theories on professionalization have been developed since the early $20^{\text {th }}$ century. For instance, professional characteristic theories represent pragmatic approaches to the issue of professionalization that focus mainly on the institutional level, namely on education and training institutions, professional institutions or a code of ethics [17-19]. Since the 1980s, however, the focus shifted to the individual level of professions, such as the professional performance [20], competencies and professional identity [16]. A combination of different approaches that distinguishes the institutional level and the individual level of professionalization was then suggested by Mieg [16]. Summarizing these different professional characteristics on institutional and individual level [16-20] leads to the following shortened listing: 1) professional performance/professional identity 2) ethics/values, 3) education/training, and 4) quality/standards/ competencies. These professional characteristics are a helpful conceptual frame for analyzing the conceptualization of the HP profession and they are thus used to derive the research questions of this scoping review, which aims to provide an overview of current developments regarding the professional characteristics of HP.

While HP is clearly a central part of $\mathrm{PH}$, it is important to consider how the two are connected [21,22]. As in HP, the professionalization discussion is also ongoing for $\mathrm{PH}$ [10,23-25]. PH deals with a great variety of issues-including prevention, health care and tackling the social determinants of health [21,26] (e.g., see 10 Essential Public Health Operations;
[27]) making $\mathrm{PH}$ very broad and complex to capture [10,26,28-30]. Moreover, $\mathrm{PH}$ is described as research orientated $[28,31]$, and still overlaid by biomedical principles $[32,33]$ whereas HP is clearly practically orientated to address the socioenvironmental determinants of health at a community level with a bio-psycho-social perspective. $\mathrm{PH}$ has to recognize the necessity of specific skills for HP [34]. There are international efforts to foster the professionalization of HP that are illustrated by several indicators found in literature [2,14,21,22,35-37] and shortly listed in Table 1. Although the specialization of competencies in HP is a desirable outcome to tackle todays' pressing health problems to foster quality standard in $\mathrm{HP}$ practice, a gradual separation between $\mathrm{PH}$ and $\mathrm{HP}$ represents a major challenge for HP and $\mathrm{PH}$ because the workforce capacity of each discipline may be reduced by a segregation of these interconnected disciplines. The professional HP development within $\mathrm{PH}$ is therefore a great concern to the workforce, which needs to be closely monitored in order to get the best of both worlds: a clear profile for HP professionals and a synergistic interplay of $\mathrm{HP}$ and $\mathrm{PH}$. We argue that identifying the professional characteristics of HP in the literature helps to foster the conceptualization of HP which contributes to the professionalization and is a prerequisite for analyzing and optimizing the interconnectedness between the $\mathrm{HP}$ and $\mathrm{PH}$ professions. The aim of this study is therefore to provide an overview of the professional characteristics of the HP profession focusing on German compared to international literature.

\section{METHODS}

Literature on HP as a profession, especially empirical studies is scarce $[11,15]$. Therefore, we conducted a scoping review as it allows the inclusion of literature of lower scientific quality such as grey literature, and is well suited to gain a broad and explorative understanding of the research question and can even help to specify it $[38,39]$.

As outlined in the introduction, a summary of different sociological professionalization theories referring to professional characteristics on the institutional and individual level [16-20] provided the conceptual background for the research questions of this scoping review. Four categories in which the professional characteristics are gathered were differentiated: 1) Professional performance/professional identity, 2) ethics/values, 3) education/training, and 4) quality/ standards/competencies. Building on the four distinct categories of the different sociological professionalization theories [16-20] described in the introduction we derived the following focal research questions:

"What does the literature reveal about ...

1) ... the profession of HP, with a focus on professional identity and professional performance?"

2) ... professional ethics/values of HP?"

3) ... education and training in HP?"

4) ... quality/standards or competencies of HP?" 
TABLE 1 | International efforts to foster the professionalization of health promotion that are illustrated by several indicators found in literature [2, 14, 21, 22, 35-37] (Professional characteristics of health promotion: a scoping review of German and international literature, Switzerland, 2021).

\section{Indicators for professionalizing $\mathrm{HP}^{\mathrm{a}}$ internationally}

1) Education and training programs in HP are established on an international level comprising bachelor's and master's degree programs and continuing education

2) Core competencies are defined in a HP framework on an international level [37]

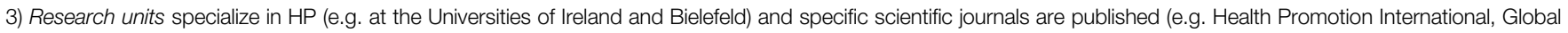
Health Promotion, Prävention und Gesundheitsförderung)

4) National and international conferences on HP are held (e.g. World Conference on HP)

5) National and international professional institutions are established, especially the International Union for Health Promotion and Education (IUHPE)

6) Accreditation systems are available and applied, such as the "IUHPE Registered Health Promotion Practitioner"

7) National and international political priorities are established on HP (e.g. UN Sustainable Development Goals (SDG 3) or the German law on prevention and HP)

${ }^{a} H P$ : health promotion.

TABLE 2 | Search strategy elaborated with PICO-scheme including search terms, synonyms and Boolean operators (Professional characteristics of health promotion: a scoping review of German and international literature, Switzerland, 2021).

\begin{tabular}{|c|c|c|}
\hline & Boolean operators & Search terms and synonyms \\
\hline $\mathbf{P}$ (opulation) & AND & Health Promotion \\
\hline I (ndicator) & & not relevant for this search strategy \\
\hline C (omparison) & NOT & Public Health \\
\hline $\mathbf{O}$ (utcome) & AND & $\begin{array}{l}\text { professional identity OR collective identity OR vocational identity OR occupational identity OR identity OR identification OR } \\
\text { profession }^{\text {a OR ethic }}{ }^{\text {a }} \text { OR value OR norm OR behavior OR standard OR competenc }{ }^{a} \text { OR frame }{ }^{a} \text {, OR quality OR profile OR } \\
\text { challenges OR education OR study OR training OR university }\end{array}$ \\
\hline
\end{tabular}

a: truncations are used to allow more search results for specific keywords

In order to systemize the search strategy, we applied the PICO scheme: P (opulation), I (ndicator), C (omparison), O (utcome of interest) [39]. Although, not all categories were relevant for the present research question, the scheme helped to specify the search strategy. All keywords, synonyms and the Boolean operators that have been used are shown in Table 2.

The search strategy employed three databases: CinahlComplete, PubMed and the International Bibliography of the Social Science (IBSS). The strategy was adapted to the search template in the database. Moreover, specific journals were screened (Global Health Promotion, Health Promotion International, Prävention und Gesundheitsförderung (German) and Spectra (Swiss) and Google Scholar was searched for grey literature. We also conducted a hand search in the references of relevant literature. The scoping review was conducted in March 2020.

Study selection was guided by inclusion criteria. We included 1) any kind of theoretical and original (empirical studies and literature reviews) literature, including journal articles and grey literature; 2) literature that focuses on HP as defined in the Ottawa Charta [1]; and 3) German as well as English literature in the review. The German literature represented a special interest of the authors who plan to conduct further research in the German speaking part of Europe (Switzerland). The inclusion of international literature supports the identification of potential opportunities and challenges within the conceptualization of the HP profession as many countries have advanced further in the professionalization of HP (e.g. Australia, New Zealand, Canada and Ireland) [6,22]. Finally, we D) limited the publication date to 2012 to 2020 as we expected the standardized competencies that were published by the IUHPE in 2011 in the CompHP core competencies framework of HP (37; German version in 2014 [40]) to impact the professionalization debate in HP. Figure 1 shows the search process including all literature identified $(N=1880)$, those who were rated as relevant after screening the abstracts $(n=119)$ and - in a second screening the full texts $(n=90)$. For the content analysis, we selected original literature only $(n=37)$.

The data was collected in an Excel file containing relevant information: author, nature of literature (journal article, grey literature), year of publication, title, methods, aim, outcome and country study conducted (see Table 3). Data analysis was based on deductive and inductive principles. Within the deductive part, we categorized the data comparable to the professional characteristics as a theoretical basis of the search strategy. The data is described quantitatively using frequencies (see Table 4). For the inductive data analysis, we conducted a content-based literature analysis, which was only applied to original literature $(n=37)$ (see Table 3$)$.

\section{RESULTS}

The search strategy revealed 90 publications, of which 31 are in German language and 59 in English of which non was conducted in a German speaking region. In total, 37 original publications (empirical studies and literature reviews) published between 2012 and 2020 were identified, 24 of which were in English. An overall lack of empirical studies on the HP profession was noteworthily, especially in the German speaking countries but also internationally. Table 4 provides further details about the descriptive analysis of the scoping review results of all 90 publications.

The content-based analyses revealed five major categories: 1) profession, 2) ethics, 3) education/training, 4) competencies and 5) quality. As the focus and content of the literature identified in the 


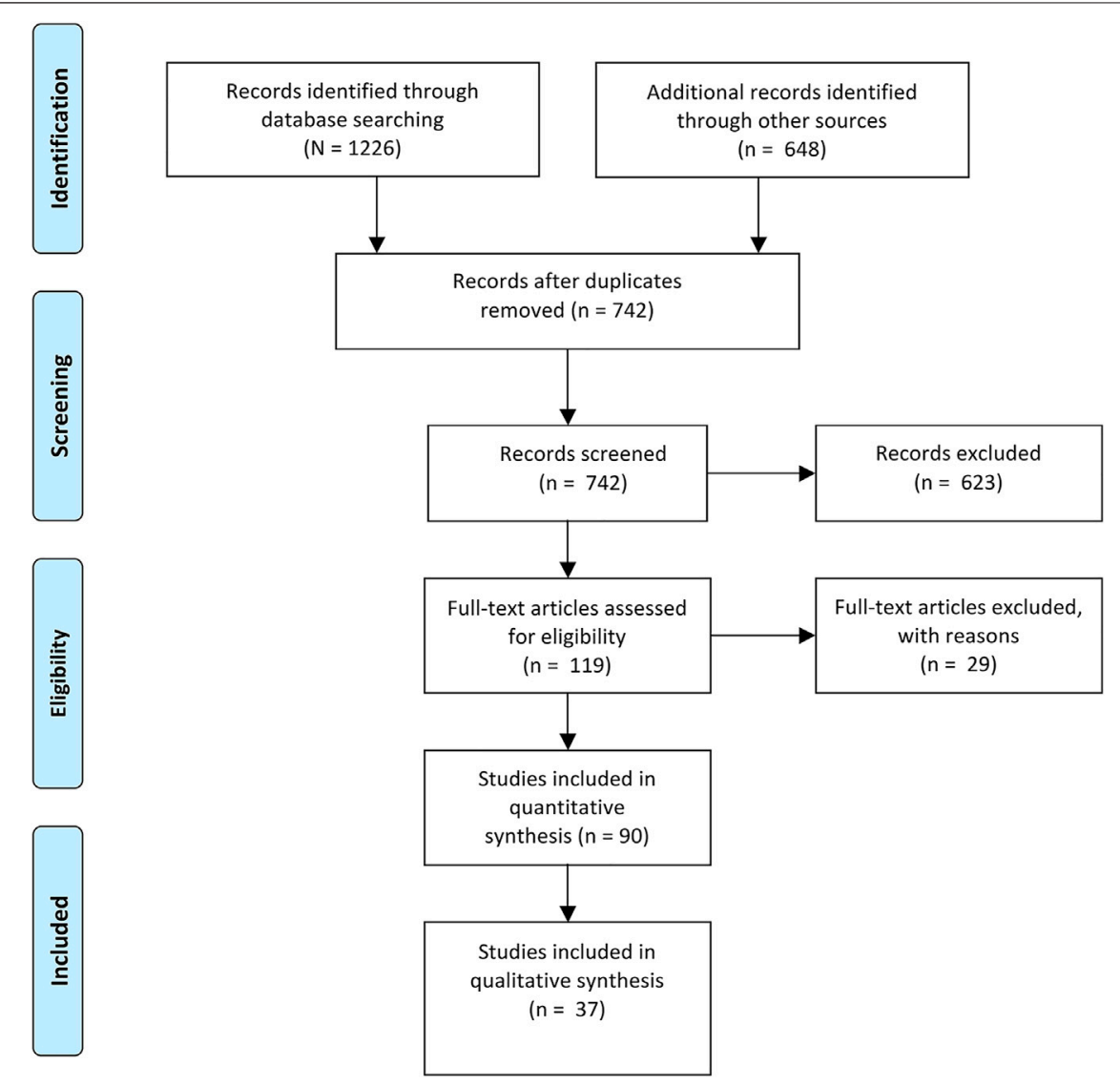

FIGURE 1 | Flowchart of literature included in the scoping review. (Professional characteristics of health promotion: a scoping review of German and international literature, Switzerland, 2021)

scoping review partly differed from the professional characteristics that have been outlined in the sociological theories, we specified and adapted the names of the categories as follows: 1) "Profession" summarizes literature focusing on HP as a profession including professional performance and professional identity; 2) "Ethics" summarizes literature regarding ethics and values of the HP profession; 3) "Education/training" summarizes literature describing training programs and study courses in HP; 4) "Competencies" was separated from 5) "Quality" as a category because there were numerous publications found which either dealt with competencies of HP professionals-or with analyzing quality standards of HP practice. The content of the original publications is summarized in the following section (see Table 3 for more details of all 37 original publications).

\section{Profession}

Three publications in German language discuss the HP profession, focusing on education of HP [41], employees' perspectives on the profession [14] and an analysis of decision makers of HP interventions in Germany [42]. Overall, the study's results show unclear definitions and roles of HP practitioners, especially when practitioners are not having an education or training in HP or a related field $[14,41]$. The variety of existing health related study courses in Germany add to the intransparency of competencies and curricula [14]. These barriers hinder the development of a professional identity and the societal acceptance of the profession [14]. Compared to the German literature, the English literature (mainly Australia, Canada and United States) seems to fulfill higher quality standards as they mostly consist of peer-reviewed journal articles. Also, with respect to the content, English articles focus on specific aspects of professional performance in HP, such as critical reflection [43], sustainable practice [44,45] and on socioecological determinants in interventions [8]. However, English and German literature are both clear about the importance of specifically trained HP competencies [8,14,42,45]. These publications variously emphasized the value of a code of ethics, a meta theory in HP and a common professional profile including professional competencies that would help to promote professionalization of HP regarding professional identity and professional performance in HP.

\section{Ethics}

All six original publications identified are published in English (mostly Australia) and focus on the ethical aspects of HP practice. Some publications focus on defining ethical dimensions of HP $[46,47]$, one focuses on challenges of empowerment applied in 
TABLE 3 Data extraction of original publications identified in the scoping review chronologically ordered by category and language published (Professional characteristics of health promotion: a scoping review of German and international literature, Switzerland, 2021).

\begin{tabular}{llllll}
\hline $\begin{array}{l}\text { Authors (nature } \\
\text { of literature) }\end{array}$ & Title & Year & Method & Aim & Outcome
\end{tabular}

\section{Category: Profession}

Zocher, U. (grey literature)

$\begin{aligned} & \text { About the challenge to study } 2013 \\ & \begin{array}{l}\text { Mixed methods } \\ \text { and teach health } \\ \text { promotion-results of }\end{array}\end{aligned}$
evaluation study

participatory evaluation

Pawlis, S., Boettcher, A., Metzner, F., Plaumann, M. and Walter, U. (journal article)

Walter, S. (master thesis)

HP on the way to a profession-an interview study
Relevance and implementation of prevention in Germany-a national survey of decision makers in health insurance association, state and communities
2015 Quantitative online survey

2015 Qualitative study using interviews
Golden, S. D. and Earp, J. A. (journal article)
Social ecological approaches 2012 Literature review to individuals and their contexts: twenty years of Health Education and Behavior health promotion interventions
Evaluating student's perspective on the profession of $\mathrm{HP}^{\mathrm{a}}$ including strength and challenges of the study course
The holistic approach of HP for some students is hard to

capture. Problematic are the diverse professional backgrounds of lecturers. Main conclusions for professionalization in HP are: 1) Expert knowledge/professional understanding (theory on HP), 2) Didactic for HP (reflective processes), 3) Leadership culture in sense of HP

Identifying the relevance and Intervention of health insurances implementation of HP and are mainly pathogenetic prevention at decision oriented, whereas interventions makers' level at health of the state are also focusing on insurance companies, the social inequities. Policy makers state and communities

Exploring the field of action and the need of HP practitioners asking experts in the field

are more positive towards capacity building in HP and prevention than health insurance companies. Main barriers are financial issues and personal resources as well as unclear roles.

HP is currently performed by a variety of professions. Most organizations employ at least one person with a professional background in health sciences, whereas related disciplines (sports, nutrition) don't see a gain for the field of action. There are also persons working in HP who don't have any specific or related training. There was agreement on the need of professionals in HP, but the diversity of study programs in Germany related to health are seen as a barrier, lacking transparent competencies. Unclear definitions of roles in HP are barriers for developing a professional identity. The study revealed clear chances of professionalization of HP, but some major challenges which seem to be solvable.

Identifying socio-ecological approaches in HP interventions published in the journal "health education and behavior" between 1989 and 2008
Germany (g)

Germany (g)

Germany (g)
United States $(e)^{c}$ on the individual and not specially on institutions,

communities or politics. Interventions in settings like schools or the community or with topics such as nutrition and physical activity were more often integrating socio-ecological approaches compared to other topics. Competencies in HP have to be strengthened in order to address socio-ecological determinants of health in interventions. 
TABLE 3 | (Continued) Data extraction of original publications identified in the scoping review chronologically ordered by category and language published (Professional characteristics of health promotion: a scoping review of German and international literature, Switzerland, 2021).

\begin{tabular}{llllll}
\hline $\begin{array}{l}\text { Authors (nature } \\
\text { of literature) }\end{array}$ & Title & Year & Method & Aim
\end{tabular}

of literature)

Harris, N. and Maria, S.

(journal article)
Defining sustainable practice in community-based health promotion: A Delphi study of practitioner perspectives

2013 Quantitative Delphi
study

$$
\begin{aligned}
& \text { Quantitati } \\
& \text { study }
\end{aligned}
$$

based HP practice

Tretheway, R., Taylor, J., A missing ethical competency? O'Hara, L. and Percival, N. A review of critical reflection in (journal article)

2015 Narrative literature review

2016 Systematic literature review services: enablers and barriers faced by organisations when increasing health promotion capacity
Legrand, K., Minary, L. and Exploration of the experiences, Briançon, S. (journal article) practices and needs of health promotion professionals when evaluating their interventions and programs
Devine, S. and Watt, K. (journal article)
2018 Quantitative written survey

\author{
Identifying definitions and \\ features of sustainable \\ practice in community- \\ based HP practice
}

Identifying enablers and barriers of primary health care organizations integrating HP approaches and capacity building of HP
Definitions of sustainable practice highlight the importance determinants, aspirations, specific features were identified: 1) effective relationships and decision making and practice, 3) emphasis on building

community capacity, 4) supportive contexts

Exploring the current use of Very limited literature exists on critical reflection in HP critical reflection in $\mathrm{HP}$, whereas its potential to support critical practice is widely acknowledged. Critical reflection is seen as a core competency for $\mathrm{HP}$ practitioners to reflect the ethical issues of HP practice. 25 articles were identified which summarize enablers for primary health care organizations:

Management support, skilled staff, committed staffing and financial resources, leadership and external partners to collaborate; barriers were the opposite of the enablers including competing priorities to HP within a health care organization which is quite often the case. Describing practices of HP
practitioners regarding evaluation of their interventions and identifying the need of an evaluation and monitoring tool of collaboration, health processes and outcomes. Four partnerships, 2) evidence-based

\section{More than half of 246} respondents in total had difficulties with conducting process evaluation. On the one hand selecting the proper evaluation tool was difficult and on the other hand a lack of time and finances. Authors identify a need for an online tool for evaluation of HP interventions. Evaluation is a major competence in HP practice.
Australia (e)

Australia (e)

Australia (e)

France (e)

\author{
Ethics in HP has substantive and \\ procedural dimensions: \\ substantive: meliorism, holism, \\ setting approach, focus on \\ primary prevention and \\ communities. Procedural: \\ interventions built on respectful \\ relationships, flexible \\ collaboration with communities, \\ and are capabilities oriented and \\ sustainable.
}

(Continued on following page) 
TABLE 3 | (Continued) Data extraction of original publications identified in the scoping review chronologically ordered by category and language published (Professional characteristics of health promotion: a scoping review of German and international literature, Switzerland, 2021).

\begin{tabular}{llllll}
\hline $\begin{array}{l}\text { Authors (nature } \\
\text { of literature) }\end{array}$ & Title & Year & Method & Aim & Outcome
\end{tabular}

Bull, T., Riggs, E. and

Nchogu, S. N. (journal

article)

Vallgarda, S. (journal article) Ethics, equality and evidence in 2014 Documental analysis

health promotion - Danish

guidelines for municipalities

Spencer, G. (journal article) "Troubling" moments in health promotion: Unpacking the ethics of empowerment
2015 Ethnographical mixed methods study
Axford, A. and Carter, D. (journal article)
Building workforce capacity for 2015 Case study ethical reflection in health promotion: a practitioner's experience
Analyzing the content of Danish national guidelines for HP regarding equity, evidence and ethical aspects

Critical analyses of the outcomes of empowerment in HP interventions, exemplified with adolescence health
Analyzing the effect of a program for capacity building in HP on the influence of ethical reflection in practice
Reilly, T., Crawford, G. Lobo, R., Leavy, J. and Jancey, J. (journal article)
Ethics and health promotion practice: exploring attitudes and practices in Western Australian health organizations
2016 Qualitative study using Analyzing attitudes, interviews practices, enablers and barriers of applied ethics in HP practice
Low response rate $(11.8 \%, N=$ 236). $83 \%$ confirmed the need of a code of ethics to clarify roles and definitions of HP. Main ethical issues are: equity, social justice and respect. The CompHP was seen as a possible basis for developing a code of ethics.

Results show a low integration of equity, evidence and ethics in the national guidelines for HP, even though it was declared as an aim of the Danish national board of health. To meet this aims in practice of HP, more effort of public health authorities is necessary.

Young adults' health priorities are set differently, e.g. smoking and drinking promotes their quality of life and selfdetermination. The different priorities raise some ethical dilemmas for HP practice regarding using empowerment. This reinforces the importance of ethical reflection of HP, especially the dimension of empowerment.

The implemented program on capacity building, which consisted of different components based on organizational change management, was evaluated by participants to have a positive impact on ethical reflection in daily practice. The ethical framework was seen as a very practical tool. Challenges for capacity building in this rural area were different professional backgrounds of HP practitioners.

Out of ten interviews, most practitioners include ethical principals in their practice. Enablers were: support with ethical applications, tools and training in ethical practice, organizational support. Barriers were: limited time resources, little knowledge, ethical application not noticed as one's task. HP practice is still lacking evidence-based practice and including ethical principles, which must be amended in the future.
International

IUHPE (e)

Denmark (e)

Australia (e)

Australia (e)

Australia (e)

(Continued on following page) 
TABLE 3 | (Continued) Data extraction of original publications identified in the scoping review chronologically ordered by category and language published (Professional characteristics of health promotion: a scoping review of German and international literature, Switzerland, 2021).

\begin{tabular}{llllll}
\hline $\begin{array}{l}\text { Authors (nature } \\
\text { of literature) }\end{array}$ & Title & Year & Method & Aim & Outcome
\end{tabular}

\section{Category: Education/training}

Sachs, I. and University of Study courses and job Applied Sciences perspectives of graduates in Neubrandenburg (grey nursing and health sciences literature)

Hartmann, T., Baumgarten, Public health and health K., Dadacynski, K. and Stolze, N. (journal article) promotion in Germany. State of development of bachelor's and master's courses
2015 Online search in data bases for health-related study programs in Germany

Continuing education and training in health promotion. A survey about intentions and conditions among participants of a countrywide seminar program in Austria

Tremblay, M. C., Richard, L., Brousselle, A. and Beaudet, N. (journal article)

How can both the intervention and its evaluation fulfill health promotion principles? An example from a professional development program

2018 Quantitative online survey

2013 Case study
Tremblay, M. C., Richard, L., Brousselle, A. and Beaudet, N. (journal article)

Learning reflexivity from a health promotion professional development program in Canada
2014 Qualitative study using interviews

Describing outcomes of reflexivity of the professional development program in HP. Implications of reflexivity for HP practice

Evaluation of health promotion

Wilkins, A., Lobo, R. C., $\begin{array}{ll}\text { Griffin, D. M. and Woods, H. } & \text { training for Western Australian } \\ \text { A. (journal article) } & \text { Aboriginal maternal and child }\end{array}$ A. (journal article)

Identifying factors influencing the intention to

2015 Quantitative evaluation study (online survey or telephone interview)

Evaluation of a HP training impact of using information
Overview of accredited study courses in public health and HP in Germany participate in continuing education and training in HP

Describing core principles of $\mathrm{HP}$, the professional development program and its evaluation ( $\mathrm{HP}$ Laboratory)
Participation of five study programs: BA health science results: $66 \%$ prior professional education (BA), 56\% satisfied, $15 \%$ dissatisfied with study program, 2/3 direct access to job, 1/3 master program, high satisfaction with job situation, broad field of actions (few in HP and prevention)

43 courses identified, 13 bachelor's and 30 master's at universities and universities of applied sciences, eight bachelor's, five master's in HP, great effort is necessary to synchronize the curriculum content

Influencing factors identified:

Self-efficacy, attitudes toward seminars, social expectations of significant others, seminar attendance in the past, interplay of personal behavior and institutional conditions

The HP Laboratory is a program to foster HP competencies in public health professionals. Participants with different professional backgrounds working in health departments developed a common understanding of HP core principles. Evaluation of the program on HP principles was challenging.

Formal and critical reflection are important methods in HP practice and helped the participants to understand their professional roles. Especially critical reflection was hard to encourage, but is important for a critical societal perspective on social justice and equity concerns in HP. for health professionals given in the training - barriers of implementing the trainings' resources in practice

2017 Case study using mixed methods students to learn focusing
Evaluation of a course in popular education method within a master's in public health. This method is supposed to train skills for a systemic analysis of power and privilege to address health and social inequities.
Low response rate $(\mathrm{N}=17)$ diverse professional backgrounds of participants; Job descriptions often with HP, but no training in HP; Chances of the training: planning tools for $\mathrm{HP}$; networking in HP; Barriers: lacking finances, low organizational support The method was very useful for United States (e) attention and creating community, cooperative learning to support accountability to one another and dramatic techniques. Barriers for using this method are students who are not used to liberal pedagogy

(Continued on following page) 
TABLE 3 | (Continued) Data extraction of original publications identified in the scoping review chronologically ordered by category and language published (Professional characteristics of health promotion: a scoping review of German and international literature, Switzerland, 2021).

\begin{tabular}{llllll}
\hline $\begin{array}{l}\text { Authors (nature } \\
\text { of literature) }\end{array}$ & Title & Year & Method & Aim
\end{tabular}

of literature)

Torres, S., Richard, L., (journal article)
Professional development Tools and processes to favor new practices
Komro, K. A., Lang, D. L., Reisinger Walker, E. and Harper, P. D. (editorial)
Integrating structural determinants into MPH training of health promotion professionals
2017 Case study using mixed methods

2018 Review of curricula of master's in public health and controversy environment of the university.

Evaluation of a professional The results showed positive development program findings implementing several which focuses on improving principles of HP (equity, holism, HP interventions including health promoting principles

Identifying structural and social determinants in curricula of master's in public health in the United States

2015 Framework
development based on
content analysis

Developing a qualification

framework for health sciences/public health and HP bachelor's and master's programs to enable comparability

2020 Interview study

Karg, S., Blättner, B. (journal article)
Competences for working in health promotion.
Speller, V., Parish, R., Davison and Zilnyk, A. (journal article)
Developing consensus on the CompHP professional standards for health promotion in Europe
2012 Mixed methods study

Description of the process of framework development (CompHP) including testing for acceptance at pan European level

Madsen, W. and Bell, T. (journal article)

Using health promotion competencies for curriculum development in higher education
2020 Case study

Analyzing chances and challenges of one institution by developing undergraduate and postgraduate courses building on national competencies of HP.
Involving nine universities a

shared framework was

developed for bachelor's

programs based on the Public

Health Action Cycle and Dublin descriptors. No consensus was found for the heterogenic master's programs.

There was agreement on professional competencies: project management, networking and teamwork, conceptual work, research, public communication, as well as social competencies. Stakeholders appreciate the holistic approach of HP practitioners.

There was a great acceptance and agreement upon the framework CompHP. This goes along with some concerns: 1) high level for practitioners, 2) developed for master's programs, 3) relationship between Public Health and HP Main chances of implementing national competencies in curricula of HP education are transparency and comparability. Challenging were organizational structures, characteristics of the study cohorts and capacity of lecturers as well as national and international expectations. One main risk is the lacking flexibility of the curriculum. This was fully obvious when CompHP was developed internationally in the meantime. The institution could restructure the curriculum again on CompHP.

(Continued on following page)
Canada (e)

United States (e)

Germany (g)

Germany (g)

United Kingdom (e)

Australia (e) 
TABLE 3 | (Continued) Data extraction of original publications identified in the scoping review chronologically ordered by category and language published (Professional characteristics of health promotion: a scoping review of German and international literature, Switzerland, 2021).

\begin{tabular}{llllll}
\hline $\begin{array}{l}\text { Authors (nature } \\
\text { of literature) }\end{array}$ & Title & Year & Method & Aim
\end{tabular}

\section{Battel-Kirk, B., Van der Developing a competency- \\ Zanden, G., Schipperen, M. based pan-european \\ Contu, P., Gallardo, C., and accreditation framework for \\ Barry, M. M. (journal article) health promotion}

2012 Mixed methods study Find consensus on including focus groups, CompHP pan-European online survey and web- accreditation framework for based consultation HP practice, education and training
2013 Quantitative written survey competencies baseline implementation survey report
2019 Scoping review promotion competencies made a difference? A scoping review of the literature
Battel-Kirk, B. and Barry, M.M. (journal article)
Battel-Kirk, B. and Barry, M. Implementation of health M. (journal article) promotion competencies in Ireland and Italy - A case study
2019 Case study including desk reviews and semistructured interviews
Battel-Kirk, B. and Barry, M.M. (journal article)
Evaluating progress in the uptake and impact of health promotion competencies in Europe
2020 Online survey conducted with consortium included in the development of CompHP
Collecting information on the current knowledge and implementation of New Zealands' HP competencies amongst the HP workforce
405 participants out of 29

countries were involved in the

study. Mainly positive agreement

on an accreditation framework

to assure quality and competence in HP. Barriers for implementation were mentioned regarding lacking resources for implementation of the accreditation framework. Furthermore, the unclear interrelationship between Public Health and HP are barriers for implementation in some countries.

105 responses revealed that $88 \%$ had at least some knowledge on the national HP competencies. The

competencies are used for personal development plans, performance reviews, planning programs. They realized an increase of clarity of their professional role and understanding of $\mathrm{HP}$. Challenges for implementing the competencies were other organizational priorities.

Explore current impact of HP competencies on practice, education and training in Europe

39 sources were identified, mainly focusing on competency frameworks and their development, some report on the use of the frameworks and only two evaluated the frameworks. There is a lack of studies on the implementation of HP competencies.

Exploring the promoting and The progress of CompHP challenging factors for implementation of CompHP at a national level comparing two countries, Ireland and Italy implementation reflected the HP infrastructure and capacity in the countries. Major limitations were a lack of awareness of the CompHP also by main stakeholders and employees. The CompHP has to be promoted over the next years to build capacity of HP.

Identify attitudes regarding the CompHP, level of Only 81 responses were received from 25 countries: attitudes were generally positive, current and intended use and opinions on their impact while only $53 \%$ confirmed the use of the CompHP in their country. The competencies were mainly used in education of HP. Main barriers for implementation of the CompHP was the lacking recognition of key organizations and stakeholder at a national level.
Europe (e)

New Zealand (e)

Ireland and Malta (e)

Ireland and

Malta (e)

Ireland and Malta (e)

\section{Category: Quality}

Wright, M. T., Noweski, M. and Robertz-Grossmann, B. (journal article)
Quality development in primary prevention and health promotion. A survey of the
Identify implementation of quality development strategies and standards
The results are very limited. Responses confirmed a great variety of quality standards used
Germany (g)

(Continued on following page) 
TABLE 3 | (Continued) Data extraction of original publications identified in the scoping review chronologically ordered by category and language published (Professional characteristics of health promotion: a scoping review of German and international literature, Switzerland, 2021).

$\begin{array}{llllll}\text { Authors (nature } & \text { Title } & \text { Year } & \text { Method } & \text { Aim }\end{array}$

of literature)

member organizations of the

Federal Association for

Prevention and Health

Promotion in Germany

Bär, G., Noweski, M., Ihm, M. and Voss, A. (journal article)

Prevention of overweight in children: Standard setting

documents
2016 Literature review and google Assessing quality standards
of overweight prevention in
children found in databases

used in HP and prevention in in HP and prevention. Therefore, Germany

Assessing quality standards

Results of a survey of

members of the Federal

Association for Prevention and

Health Promotion
2016 Qualitative study using expert interviews
Exploring the current status of quality standards used in $\mathrm{HP}$ and prevention standards used in HP and
Reisig, V., Kuhn, J., Loos, S., Nennstiel-Ratzel, U., Wildner, M. and Caselmann, W. H. journal article)
Primary prevention and health promotion in Bavaria: Taking stock
2016 Mixed methods approach including an online survey and expert interviews
Assessing the status quo of prevention and HP in Bavaria, aiming at a qualityoriented development of the field
2018 Qualitative study using expert interviews
Identifying the need of common quality standards for HP and prevention the questionnaire could not be answered properly. The authors concluded that a qualitative research approach is necessary to capture the variety of quality prevention.

German literature on quality standards and overweight prevention in children is rare. Standard setting documents of key stakeholders of HP and prevention in Germany are comparable with each other but do not refer to each other. Moreover, it is not clear which document guides the quality standards for overweight prevention in children in Germany.

42 experts were interviewed:

Using quality standards in practice correlates with financial resources and qualified staff in the institutions. Good practice examples would be a helpful tool as well as a nationwide monitoring system. First, more funding is required for assuring quality standards in practice.

HP and prevention practice mainly address health literacy and mental health issues by providing health information relating to behavior change interventions. Rather low is the engagement with gender specific topics or socially disadvantaged groups including working with a setting approach in communities. About half of the participants include scientific results in their project development and $43 \%$ conduct evaluations.

A common quality standard is meaningful to the interviewed experts. A complex and challenging process to identify this common standard is expected to meet specific needs of different topics within HP and prevention. Even within these expert interviews no theoretical saturation could be revealed because expectation varied meaningfully.
Germany (g)

Germany (g)

Germany (g)

Germany (g)
A., Ihm, M. and Fricke, L. primary prevention. The expert (journal article) primary preven
survey PräKiT

Country 
HP interventions [48]. Further publications accentuate the importance of the implementation of ethics into HP practice $[49,50]$ and also national guidelines for HP [51]. It is evident that there is a substantial gap between theory and practice regarding HP ethics, despite ethical considerations being mandatory when planning and conducting interventions. As already recognized within the category "profession," a code of ethics in HP is needed and asked for $[41,46-48,50,51]$.

\section{Education/Training}

In total, nine original publications were identified that fit the category "education/training." German as well as English publications display a broad spectrum of thematic aspects. Some publications evaluate professional training programs in HP for different professions [52-56]. These publications demonstrate that persons employed in HP often don't have any professional knowledge about it [55]. There are also publications that study the HP competencies within a master's program in Public Health [32,57], which reveal major gaps in the curriculum addressing social determinants of health [32]. Finally, only a few publications focused on academic study programs in HP. Only two were found from German speaking regions $[58,59]$ and these studies are not exclusively focusing on HP but also included related study topics courses.

\section{Competencies}

Competencies are the basis for professional performance. In total, nine publications were identified focusing on competencies in HP, two of them in German. The German publications don't focus on the CompHP $[60,61]$ but developed an inclusive framework for $\mathrm{PH}$, health sciences and HP study programs [59]. Most English publications focus on the development and implementation of the CompHP [6,62-64], which is also adapted as an accreditation framework for HP practitioners [65]. Australia [66] and New Zealand [67] also edited own frameworks. The importance of common professional competencies is affirmed by all authors [6,60-66]. It is seen as the basis for a common professional profile, for transparent professional competencies, for a common code of ethics and strong professional identities as HP practitioners [63]. For more detailed literature on the competencies, Battel-Kirk's and Barry's scoping review from 2019 can be consulted [63].

\section{Quality}

All five original publications focusing on quality assurance of $\mathrm{HP}$ and prevention interventions included in the content analysis of this scoping review were conducted in Germany. Their overall aim was to identify quality standards that can be used by primary stakeholders in HP and prevention [68-71]. Quality assurance of HP and prevention interventions are still fragmented and poorly standardized, although a standardization of tools and activities is agreed upon when resources are available. Regarding the quality of HP interventions as defined in the Ottawa Charta, one article detected an insufficient focus on social determinants of health or on projects based on the setting approach but a strong focus on behavior change programs [7].

\section{DISCUSSION}

This scoping review aimed to outline the actual developments of professional characteristics of HP with a focus on the German speaking part of Europe taking international literature into account. Of 90 publications that were identified, 37 were original publications and about one-third of the theoretical and original publications were contributions from the German speaking context. Based on the content-analysis, the results were summarized in categories that reflect the professional characteristics: 1) profession, 2) ethics, 3) education/training 4) competencies, and 5) quality. Content analysis was only applied to the original literature $(n=37)$. Overall, HP is clearly developing as a profession especially in English speaking countries, as literature was identified regarding all professional characteristics [16] with the exception of the professional identity of HP practitioners. German original literature did not address "ethics" as a professional characteristic and only few publications considering "competencies" and "education/training" were identified. Thus, the discussion in the German original literature was mostly focused on the two specific professional characteristics of "education/training" and "quality." Furthermore, the quality of the German literature was lower than the international literature (i.e., more grey literature than peer-reviewed articles). Summing up the findings, the importance of a common code of ethics in HP, a meta theory in HP and a common professional profile including professional competencies are needed to promote professionalization of HP regarding professional identity and professional performance of HP practitioners.

In total, German original literature revealed that HP is rather unclear in its conception and establishment as a profession, as well as in terms of its relation to $\mathrm{PH}$. The following factors contribute to the confusion and intransparency of HP at an educational level, within the labor market and in society. As described in the introduction HP is not mentioned to be an exclusive profession but is seen as a paradigm shift of our health system [1]. Therefore, on the one hand a wide range of professions (doctors, nurses, therapists, teachers, social workers etc.) are called to promote health and integrate the principles of the Ottawa Charta in their professional work: participation, empowerment, and health equity. On the other hand, we need HP professionals to initiate this paradigm shift, conduct specific HP projects and mediate between important stakeholder to foster Health in all Policies [12,34]. This can be contradictory and in conflict with the goal to define clear professional roles. There is a lack of studies describing the contents and learning outcomes of HP programs, which are needed to promote comparability and transparency of the programs to define the professional roles of HP practitioners. The confusion about health-related courses is reinforced by a great expansion of these programs since the Bologna process in 1999. Study programs are named very differently (health sciences, health communication, public health, health management, health promotion etc.) but competencies and curricula are overlapping $[26,72,73]$ and seem to qualify students for HP practice. Educational institutions competitively advertise for potential 
TABLE 4 | Descriptive analysis of data included in the scoping review (Professional characteristics of health promotion: a scoping review of German and international literature, Switzerland, 2021).

\begin{tabular}{|c|c|c|c|}
\hline & \multirow{2}{*}{$\frac{\text { Total }}{\mathbf{N}}$} & \multicolumn{2}{|c|}{ Language } \\
\hline & & German & English \\
\hline & $90(100 \%)$ & $31(34.4 \%)$ & 59 (65.6\%) \\
\hline \multicolumn{4}{|l|}{ Form of literature } \\
\hline Theoretical & 53 (58.9\%) & 18 (20.0\%) & 35 (38.9\%) \\
\hline Original article & 37 (41.1\%) & $13(14.4 \%)$ & $24(26.7 \%)$ \\
\hline \multicolumn{4}{|l|}{ Categories } \\
\hline Profession & 34 (37.8\%) & 10 (11.1\%) & $24(26.7 \%)$ \\
\hline Theoretical & 26 & 7 & 19 \\
\hline Original article & 8 & 3 & 5 \\
\hline Ethics & 21 (23.3\%) & $5(5.6 \%)$ & $16(17.8 \%)$ \\
\hline Theoretical & 15 & 5 & 10 \\
\hline Original article & 6 & - & 6 \\
\hline Education/training & 16 (17.8\%) & $6(6.7 \%)$ & $10(11.1 \%)$ \\
\hline Theoretical & 7 & 3 & 4 \\
\hline Original article & 9 & 3 & 6 \\
\hline Competencies & 12 (13.3\%) & $4(4.4 \%)$ & $8(8.9 \%)$ \\
\hline Theoretical & 3 & 2 & 1 \\
\hline Original article & 9 & 2 & 7 \\
\hline Quality & 7 (7.8\%) & $6(6.7 \%)$ & $1(1.1 \%)$ \\
\hline Theoretical & 2 & 1 & 1 \\
\hline Original article & 5 & 5 & - \\
\hline
\end{tabular}

students with a great variety of study programs which is fostered since the Bologna process. Mainstreaming of HP can be recognized in many health-related study courses. This mainstreaming of $\mathrm{HP}$ in diverse sectors of health $[2,22,74]$ may lead to loss of quality of HP practice. To establish an efficient $\mathrm{PH}$ system including a strong $\mathrm{HP}$ workforce, collaboration with a common language has to be the goal instead of competing interests and economic factors at educational institutions. More specific HP programs must be established at universities with staff engaged in HP research and practice. $\mathrm{PH}$ has to recognize the specific competencies for $\mathrm{HP}$, which are not sufficiently addressed in general $\mathrm{PH}$ programs, even less in other health professions' programs [34]. Literature identified in the scoping review conclude that higher education institutions are meant to play a significant role to clarify HP's roles, promote its societal status and coordinate initiatives to overcome the mainstreaming of HP $[12,14,41]$.

Concerns about the quality of HP and prevention in practice were identified in German original literature in terms of the poor standards in planning, conducting and evaluating HP interventions [7,68-71]. Most interventions are not based on a setting approach and do not focus on social determinants of health at a community level but address individual behavior change instead [7]. Of course, the debate about the quality in HP practice is inherently linked with competencies and the education or training of persons working in the field. Both, the German and English literature point out that there is a lack of expertise and professional knowledge in HP practice
$[6,7,14,42,45]$. Therefore, the CompHP framework by the IUHPE is a good basis to build on, for educational purposes, for the labor market to prioritize professional profiles, as well as for governmental guidelines for HP [37]. The international literature reveals few publications on competencies in HP, mostly the CompHP, but the implementation in the different countries is progressing slowly $[6,64]$. The German version of the CompHP was published in 2014 [75]. Whereas original literature showed no reference to the CompHP in 2015 [60], theoretical publications in 2018 indicate the rising recognition of the CompHP also in the German speaking part of Europe [75,76]. Battel-Kirk and Barry (2019) point out that the implementation progress of the CompHP reflects the professionalization of HP in the particular country $[6,64]$. The competency framework for HP is meant to strengthen professional identity and roles of the HP workforce [63]. Major challenges for the implementation are structural aspects, e.g. political commitment to HP, lacking differentiation between $\mathrm{HP}$ and $\mathrm{PH}$, a weak HP workforce and lacking knowledge about the CompHP. Facilitators are a strong HP professional institution, national accreditation of HP and HP education $[6,63]$. Therefore, the CompHP influences all professional characteristics of HP, namely professional performance and professional identity, ethics/values, education/training and competencies/quality. Two further initiatives are mentioned which promote clarification regarding the professional characteristics of HP: Quality of HP practice in the German speaking countries is enhanced by "Quintessenz" a widely known online network and projectmanagement-tool, which ensures a systematic and high quality proceeding in HP practice [77]. An internationally committed code of ethics in HP still needs to be established. Besides the CompHP the code of ethics of health education professionals in the United States [78] can also be drawn upon. There have been made great professional achievements in HP within the last years (see Table 1). Therefore, we need a young professionally trained HP workforce to further promote their visibility and competencies to address actual and future challenges of society's health.

\section{Limitations}

Searching the databases and journals revealed an abundance of English literature but a scarcity of German literature. Therefore, we conducted an extended search for grey literature in Google Scholar and a hand search for the German literature. This may have led to an increased amount of grey literature in the German relative to the English literature. As the main aim of the scoping review was to identify professional characteristics of $\mathrm{HP}$ in the German speaking part of Europe with comparison to the international literature, this limitation should not invalidate the findings. Further, abstracts and full texts were only singlescreened, which represents a methodological limitation. However, this proceeding is often applied in scoping reviews and can even be justified for systematic reviews [79]. 


\section{Conclusion}

Analyzing international literature on professional characteristics of HP reveals the necessity of clarifying competencies and the professional profile of HP. The lack of expertise and professional knowledge in HP practice in the German speaking part of Europe as well as internationally $[6,7,14,41,44]$ indicates the need for clarification regarding specialized competencies of HP within the $\mathrm{PH}$ field. Therefore, integrating the CompHP in national and regional HP institutions, at an educational level, as well as in relation to the workforce and labor market would help to address these needs. The lack of recognition of the CompHP is evident in the identified literature, especially in the German speaking countries, and must be of concern in future investigations on the HP profession. The unclear relationship and differentiation between HP and PH further hinders the conceptualization of the HP profession [6,62]. Higher education institutions play a major role in clarifying the interconnectedness between $\mathrm{HP}$ and $\mathrm{PH}$, addressing this by adapting curricula and names of their study programs. HP as a profession and HP professionals would benefit from being trained based on the CompHP, which reflects professional competencies for HP based on the Ottawa Charta. Transparency and comparability of competencies of the HP, PH and the wider health workforce contribute to the political and societal recognition of important

\section{REFERENCES}

1. WHO. Ottawa Charta for Health Promotion. Ottawa: World Health Organization; (1986).

2. Kickbusch, I, and Nutbeam, D. A Watershed for Health Promotion. Health Promot Int (2017). 32(1):2-6. doi:10.1093/heapro/daw112

3. Transforming, UN. Our World: The 2030 Agenda for Sustainable Development. [Internet]. New York, NY: United Nations (2015). [cited 2020 May 23]. Available from: https://www.un.org/ga/search/view_doc.asp?symbol=A/RES/ $70 / 1 \&$ Lang=E.

4. Kickbusch, I. 21st century Determinants of Health and Wellbeing: a New challenge for Health Promotion. Glob Health Promot (2012). 19(3):5-7. doi: $10.1177 / 1757975912454783$

5. T Schott and C Hornberg, editors. Die Gesellschaft und ihre Gesundheit: 20 Jahre Public Health in Deutschland: Bilanz und Ausblick einer Wissenschaft. 1. Aufl. Wiesbaden: VS Verlag für Sozialwissenschaften (2011). p. 682 (Gesundheit und Gesellschaft).

6. Battel-Kirk, B, and Barry, MM. Implementation of Health Promotion Competencies in Ireland and Italy-A Case Study. IJERPH (2019). 16(24): 4992. doi:10.3390/ijerph16244992

7. Reisig, V, Kuhn, J, Loos, S, Nennstiel-Ratzel, U, Wildner, M, and Caselmann, W. Primärprävention und Gesundheitsförderung in Bayern - eine explorative Bestandsaufnahme. Gesundheitswesen (2016). 79(04):238-46. doi:10.1055/s0042-108585

8. Golden, SD, and Earp, JAL. Social Ecological Approaches to Individuals and Their Contexts. Health Educ Behav (2012). 39(3):364-72. doi:10.1177/ 1090198111418634

9. Paccaud, F, Weihofen, A, and Frank, M. Public Health Workforce in Switzerland: Are Public Health Workers Lacking? Int J Public Health (2013). 58(6):799-800. doi:10.1007/s00038-013-0481-2

10. Hommes, F, Alpers, K, Reime, B, and Rexroth, U. Durch attraktive Karrierewege Public Health in Deutschland nachhaltig stärken - Kernforderungen an eine Public-Health-Strategie für Deutschland im Bereich Human Resources. Gesundheitswesen (2020). 82(04):303-5. doi:10.1055/a-1082-0890 professions in national and international efforts to tackle rising social inequalities of health and global health issues (infectious and non-communicable diseases).

\section{AUTHOR CONTRIBUTIONS}

VB developed the conceptual idea, conducted the scoping review and wrote the manuscript. TG supervised the project and contributed to the manuscript. FW contributed substantially to the conceptual idea of the project and the manuscript and supervised the project.

\section{CONFLICT OF INTEREST}

The authors declare that the research was conducted in the absence of any commercial or financial relationships that could be construed as a potential conflict of interest.

\section{ACKNOWLEDGMENTS}

We would like to thank Victoria Saint for proof reading and editing the English of the manuscript.

11. Walther, K. Professionspfade in der Gesundheitsförderung. Analysen zur gesundheitsfördernden Arbeit in Arbeitsmarkt, Ausbildung und Beruf. Osnabrück. Der andere Verlag (2002).

12. Göpel, E. Professionalisierung der Gesundheitsförderung und mögliche Konsequenzen für die Aus- und Weiterbildung der Gesundheitsberufe. In Professionalisierung im Gesundheitswesen. Bern: Hans Huber. Hogrefe AG (2006). p. 159-74.

13. Bals $\mathrm{T}$, and Wulfhorst, B. Gesundheitsförderung als Beruf. In: Gesundheitsförderung in pädagogischen Settings. Weinheim, München: Juventa (2008). p. 113-33.

14. Walter, S. Gesundheitsförderung auf dem Weg zur Profession - eine

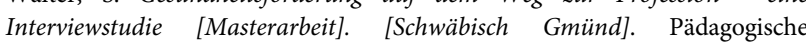
Hochschule Schwäbisch Gmünd (2015).

15. Streckeisen U. Gesundheitsförderung als Beruf? Aspekte der Ausbildung, Beschäftigung und Berufspolitik hinsichtlich Public Health. In Alte und neue Gesundheitsberufe. Zürich: Lit Orlux (2013).

16. Mieg, H. Profession: Begriff, Merkmale, Gesellschaftliche Bedeutung. In: M Dick, W Marotzki, and H Mieg, editors. Handbuch Professionsentwicklung. Bad Heilbrunn. Verlag Julius Klinkhardt (2016). p. 27-40.

17. Carr-Saunders, AM, and Wilson, PA. The Professions. 1. Oxford: Clarendon Press (1933).

18. Wilensky, HL. The Professionalization of Everyone? Am J Sociol (1964). 70(2): 137-58. doi:10.1086/223790

19. Beck, U, Brater, M, and Daheim, H. Soziologie der Arbeit und der Berufe: Grundlage, Problemfelder, Forschungsergebnisse. Reinbek bei HamburgRowohlt (1980).

20. Oevermann, U. Theoretische Skizze einer revidierten Theorie professionellen Handelns. In Pädagogische Professionalität Untersuchungen Zum Typus Pädagogischen Handelns. Frankfurt: Suhrkamp (1996). p. 276-302.

21. Faltermaier, T, and Wihofszky, P. Gesundheitsförderung und Prävention im Kontext von Public Health. In: Schott T, Hornberg C, editors. Die Gesellschaft und ihre Gesundheit. Wiesbaden: Springer (2011). p. 257-74.

22. Van Den Broucke, S. Strengthening Health Promotion Practice: Implementation Systems and Capacity Development [Internet]. Workshop: Health Promotion: An Integrative Paradigm for Sustainable Health, Wellbeing and Development Presented at: World Congress on Public Health (2020). [cited 2020 Nov 19]; Rome (online). 
Available from: https://www.iuhpe.org/images/IUHPE/News/WCPH2020/WCPH_ Van-den-Broucke_13_oct_6E.pdf.

23. Czabanowska K, Laaser U, and Stjernberg, L. Shaping and authorising a public health profession. South Eastern European Journal of Public Health (SEEJPH). (2014).(2).

24. Gershuni, O, Czabanowska, K, Burazeri, G, Cichowska Myrup, A, and Von Krauss, MK. Is There a golden Recipe? A Scoping Review of Public Health Workforce Development. Eur J Public Health (2019). 29(3):401-8. doi:10.1093/eurpub/cky247

25. Foldspang, A. Towards a Public Health Profession: the Roles of Essential Public Health Operations and Lists of Competences. Eur J Public Health (2015). 25(3):361-2. doi:10.1093/eurpub/ckv007

26. Gerlinger, T, Babitsch, B, Blättner, B, Bolte, G, Brandes, I, Dierks, M-L, et al. Situation und Perspektiven von Public Health in Deutschland Forschung und Lehre. Gesundheitswesen (2012). 74(11):762-6. doi:10.1055/s-0032-1330011

27. WHO. The 10 Essential Public Health Operations [Internet] (2020). [cited 2020 Nov 11]. Available from: https://www.euro.who.int/en/health-topics/ Health-systems/public-health-services/policy/the-10-essential-publichealth-operations.

28. Adelberger, BC. Anforderungen im Arbeitsmarkt Public Health. Anregungen für die curriculare Schwerpunktsetzung im Fachbereich [Dissertation]. Berlin]: TU Berlin (2013).

29. Hinz, J. Akademisierung von Gesundheit(-sberufen) - Chancen, Herausforderungen und Perspektiven der Public Health-Ausbildung für das Berufsfeld Gesundheit. In Eine Markt- und Potenzialanalyse [Dissertation]. [Bielefeld]. Universität Bielefeld (2018).

30. Dierks, M. Aus-, Fort- und Weiterbildung in Public Health - wo stehen wir heute?: Plenarvortrag im Rahmen des Zukunftsforums Public Health. Berlin 2016 Gesundheitswesen (2017). 79(11):954-9.

31. Lorenz, H-J, and Pundt, J. Professionalisierung durch Public Health - Eine Verbleibsanalyse Berliner Public Health-Absolventen. Jahrbuch für Kritische Medizin und Gesundheitswissenschaften. (2002). 37:96-118.

32. Komro, KA, Lang, DL, Walker, ER, and Harper, PD. Integrating Structural Determinants into MPH Training of Health Promotion Professionals. Am J Public Health (2018). 108(4):477-9. doi:10.2105/ajph.2018.304309

33. McQueen, DV, and Kickbusch, I. Introduction. In Health \& Modernity. New York: Springer (2007). p. 1-5. doi:10.1007/978-0-387-37759-9_1

34. Kemm, J. Health Promotion: Ideology, Discipline, and Specialism. Oxford University Press (2014). doi:10.1093/med/9780198713999.001.0001

35. Kaba-Schönstein, L. Gesundheitsförderung 3: Entwicklung nach Ottawa. Leitbegriffe der Gesundheitsförderung und Prävention: Glossar zu Konzepten [Internet] (2018). [cited 2020 Nov 19]; Available from: https://www.leitbegriffe. bzga.de/systematisches-verzeichnis/kernkonzepte-und-entwicklungen-dergesundheitsfoerderung/gesundheitsfoerderung-iii-internationale-entwicklunghistorische-und-programmatische-zusammenhaenge-nach-ottawa-1986-bisheute.

36. Studiengang Gesundheitsförderung und -management in Europa. Professionalisierung der Gesundheitsförderung: Bilanzierung von Policy-, Praxis- und Wissenschaftsentwicklung auf dem Weg zur nachhaltigen Gesundheitsförderung in Deutschland, Österreich und der Schweiz. Hochschulen für Gesundheit (2012).

37. Dempsey, C, Battel-Kirk, B, and Barry, MM. CompHP Project Partners. The CompHP Core Competencies Framework for Health Promotion (Short Version). IUHPE (2011).

38. Arksey, H, and O'Malley, L. Scoping Studies: towards a Methodological Framework. Int J Soc Res Methodol (2005). 8(1):19-32. doi:10.1080/ 1364557032000119616

39. Tricco, AC, Lillie, E, Zarin, W, O’Brien, KK, Colquhoun, H, Levac, D, et al. PRISMA Extension for Scoping Reviews (PRISMA-ScR): Checklist and Explanation. Ann Intern Med (2018). 169(7):467-73. doi:10.7326/m180850

40. Barry MM, ed. Bundeszentrale für gesundheitliche Aufklärung, Das CompHPRahmenkonzept für die Gesundheitsförderung: Kernkompetenzen-professionelle Standards-Akkreditierung. Deutsche Kurzfassung. Aufl: 1.2.03.14. Köln: BZgA (2014). p. 44. (Konzepte). Available at: https://www.bzga.de/infomaterialien/ fachpublikationen/fachpublikationen/band-5-das-comphp-rahmenkonzept-fuerdie-gesundheitsfoerderung/.
41. Zocher, U. Über die Herausforderung Gesundheitsförderung zu studieren und zu lehren - Ergebnisse partizipativer Begleitforschung. [Internet]. Dossenheim (2013). [cited 2020 Mar 1]. Available from: http://www.gesundheitsfoerderung-studieren.de/ images/pdf/synopse_2008-2012_UZ-1\%20Kopie\%20.pdf.

42. Pawils, S, Boettcher, A, Metzner, F, Plaumann, M, and Walter, U. Stellenwert und Umsetzung der Prävention in Deutschland - Eine bundesweite Befragung von Entscheidungsträgern in GKV-Spitzenverband, Bund, Ländern und Kommunen. Gesundheitswesen (2015). 77(S 01):S12-S13. doi:10.1055/s-0035-1559611

43. Tretheway, R, Taylor, J, O'Hara, L, and Percival, N. A Missing Ethical Competency? A Review of Critical Reflection in Health Promotion. Health Promot J Austr (2015). 26(3):216-21. doi:10.1071/he15047

44. Harris, N, and Sandor, M. Defining Sustainable Practice in Community-Based Health Promotion: A Delphi Study of Practitioner Perspectives. Health Promot J Austr (2013). 24(1):53-60. doi:10.1071/he12908

45. McFarlane, K, Judd, J, Devine, S, and Watt, K. Reorientation of Health Services: Enablers and Barriers Faced by Organisations when Increasing Health Promotion Capacity. Health Promot J Austr (2016). 27(2):118-33. doi:10.1071/he15078

46. Bull, T, Riggs, E, and Nchogu, SN. Does Health Promotion Need a Code of Ethics? Results from an IUHPE Mixed Method Survey. Glob Health Promot (2012). 19(3):8-20. doi:10.1177/1757975912453181

47. Carter, SM, Klinner, C, Kerridge, I, Rychetnik, L, Li, V, and Fry, D. The Ethical Commitments of Health Promotion Practitioners: An Empirical Study from New South Wales, Australia. Public Health Ethics (2012). 5(2):128-39. doi:10.1093/phe/phs014

48. Spencer, G. 'Troubling' Moments in Health Promotion: Unpacking the Ethics of Empowerment. Health Promot J Austr (2015). 26(3):205-9. doi:10.1071/ he15049

49. Reilly, T, Crawford, G, Lobo, R, Leavy, J, and Jancey, J. Ethics and Health Promotion Practice: Exploring Attitudes and Practices in Western Australian Health Organisations. Health Promot J Austr (2016). 27(1):54-60. doi:10.1071/he15059

50. Axford, A, and Carter, D. Building Workforce Capacity for Ethical Reflection in Health Promotion: a Practitioner's Experience. Health Promot J Austr (2015). 26(3):222-30. doi:10.1071/he15031

51. Vallgarda, S. Ethics, equality and Evidence in Health Promotion Danish Guidelines for Municipalities. Scand J Public Health (2014). (42) 337-43. doi:10.1177/1403494814525007

52. Lang, G, and Gajar, P. Fort- und Weiterbildung in der Gesundheitsförderung: Eine Befragung über Absichten und Bedingungen unter Teilnehmern eines österreichweiten Seminarprogramms. Präv Gesundheitsf (2018). 13(1):24-31.

53. Tremblay, M-C, Richard, L, Brousselle, A, and Beaudet, N. Learning Reflexively from a Health Promotion Professional Development Program in Canada. Health Promot Int (2013). 29(3):538-48. doi:10.1093/heapro/dat062

54. Torres S, Richard L, Guichard A, Chiocchio F, Litvak E, and Beaudet N. Professional Development Programs in Health Promotion: Tools and Processes to Favor new Practices. Health Promot Int (2017).(32) 587-98. doi:10.1093/heapro/dav097

55. Wilkins, A, Lobo, RC, Griffin, DM, and Woods, HA. Evaluation of Health Promotion Training for the Western Australian Aboriginal Maternal and Child Health Sector. Health Promot J Austr (2015). 26:57-63.

56. Tremblay, M-C, Richard, L, Brousselle, A, and Beaudet, N. How Can Both the Intervention and its Evaluation Fulfill Health Promotion Principles? an Example from a Professional Development Program. Health Promot Pract (2013). 14(4):563-71. doi:10.1177/1524839912462030

57. Wiggins, N, and Pérez, A. Using Popular Education with Health Promotion Students in the USA. Health Promot Int (2017). 32:660-70. doi:10.1093/ heapro/dav121

58. Hartmann, T, Baumgarten, K, Dadaczynski, K, and Stolze, N. Gesundheitswissenschaften/Public Health und Gesundheitsförderung in Deutschland. Präv Gesundheitsf (2015). 10(3):239-46. doi:10.1007/s11553015-0495-0

59. Sachs I, Hochschule Neubrandenburg, editors. Studium, Studienverlauf und Berufsperspektiven von Absolventinnen und Absolventen Pflege- und Gesundheitswissenschaftlicher Studiengänge. Neubrandenburg: Hochschule Neubrandenburg (2014). p. 178 (Schriftenreihe der Hochschule Neubrandenburg G).

60. Baumgarten, K, Blättner, B, Dadaczynski, K, and Hartmann, T. Entwicklung eines Fachqualifikationsrahmens für die Studienbereiche Gesundheitswissenschaften/ 
Public Health und Gesundheitsförderung in Deutschland. Präv Gesundheitsf (2015). 10(4):320-7. doi:10.1007/s11553-015-0507-0

61. Karg S, Blättner B, Krüger K, and Micheew N. Kompetenzen für Tätigkeiten in der Gesundheitsförderung: Sichtweisen von Stakeholdern. Präv Gesundheitsf. (2020).(15):236-41.

62. Speller, V, Parish, R, Davison, H, and Zilnyk, A. Developing Consensus on the CompHP Professional Standards for Health Promotion in Europe. Health Educ Behav (2012). 39(6):663-71. doi:10.1177/1090198112467802

63. Battel-Kirk, B, and Barry, MM. Has the Development of Health Promotion Competencies Made a Difference? A Scoping Review of the Literature. Health Educ Behav (2019). 46(5):824-42. doi:10.1177/1090198119846935

64. Battel-Kirk, B, and Barry, MM. Evaluating Progress in the Uptake and Impact of Health Promotion Competencies in Europe. Health Promot Int (2020). 35(4): 779-89.

65. Battel-Kirk, B, Van der Zanden, G, Schipperen, M, Contu, P, Gallardo, C, Martinez, A, et al. Developing a Competency-Based Pan-European Accreditation Framework for Health Promotion. Health Educ Behav (2012). 39(6):672-80. doi:10.1177/1090198112466664

66. Madsen, W, and Bell, T. Using Health Promotion Competencies for Curriculum Development in Higher Education. Glob Health Promot (2012). 19(1):43-9. doi:10.1177/1757975911428818

67. Hicks, K. Ngā Kaiakatanga Hauora Mō Aotearoa - Health Promotion Competencies for Aotearoa New Zealand. [Internet]. Auckland: Healh Promotion Forum of New Zealand (2013). [cited 2020 Apr 10] p. 6. Available from: http://www.hauora.co.nz/assets/files/Health\%20Promotion\% 20Competencies $\% 20 \% 20$ Final.pdf.

68. Bär, G, Noweski, M, Ihm, M, and Voss, A. Übergewichtsprävention bei Kindern: Standard setzende Dokumente. Bundesgesundheitsbl (2016). 59(11):1405-14. doi:10.1007/s00103-016-2450-4

69. Grossmann, B, and Noweski, M. Qualität in der Primärprävention. Ergebnisse einer Mitgliederbefragung der Bundesvereinigung Prävention und Gesundheitsförderung e. V. Gesundh Ökon Qual Manag (2016). 21(03):163-7.

70. Noweski, M, Bär, G, Voss, A, Ihm, M, and Fricke, L. Qualitätsstandards in der Primärprävention. Präv Gesundheitsf (2018). 13(2):97-102. doi:10.1007/ s11553-017-0630-1
71. Wright, MT, Noweski, M, and Robertz-Grossmann, B. Qualitätsentwicklung in Primärprävention und Gesundheitsförderung. Praev Gesundheitsf (2012). 7(1):11-7. doi:10.1007/s11553-011-0317-y

72. Bollinger, H, Gerlach, A, and Pfadenhauer, M. Soziologie und Gesundheitsberufe. In Gesundheitsberufe im Wandel. 4. Frankfurt am Main: Mabuse-Verlag (2016). p. 7-12.

73. Borgetto, B. Ausbildung, Akademisierung und Professionalisierung der therapeutischen Gesundheitsberufe in Deutschland. In Alte und neue Gesundheitsberufe. Zürich: Lit Orlux (2013). p. 138-60.

74. Jackson, SF. Mainstreaming Health Promotion. Glob Health Promot (2011). 18(2):03-4. doi:10.1177/1757975911404642

75. Szabo, B, Gollner, E, and Schnabel, F. Personalisiertes und forschungsgeleitetes Lehren und Lernen als integrale Bestandteile der Lehr- und Lernstrategie des Masterstudienganges "Gesundheitsförderung und Gesundheitsforschung" an der Fachhochschule Burgenland. Pädagogik der Gesundheitsberufe. (2018). 1:8.

76. Niederberger, M, and Kahlert, D. Forschendes Lernen in der Methodenlehre: Eine Diskussion anhand eines Fallbeispiels aus der Gesundheitsförderung. die hochschullehre (2018). 4:531-51.

77. Kolip P, Ackermann G, Ruckstuhl B, and Studer, H. Gesundheitsförderung mit System. 2nd ed. Bern: Hogrefe (2019).

78. Coalition for National Health Education Organizations (CNHEO). Code of Ethics for the Health Education Profession [Internet] (2020). [cited 2021 Jan 4]. Available from: https://assets.speakcdn.com/assets/2251/CodeofEthicsfull2020.pdf.

79. Waffenschmidt, S, Knelangen, M, Sieben, W, Bühn, S, and Pieper, D. Single Screening versus Conventional Double Screening for Study Selection in Systematic Reviews: a Methodological Systematic Review. BMC Med Res Methodol (2019). 19(1):132. doi:10.1186/s12874-019-0782-0

Copyright (c) 2021 Biehl, Gerlinger and Wieber. This is an open-access article distributed under the terms of the Creative Commons Attribution License (CC $B Y)$. The use, distribution or reproduction in other forums is permitted, provided the original author(s) and the copyright owner(s) are credited and that the original publication in this journal is cited, in accordance with accepted academic practice. No use, distribution or reproduction is permitted which does not comply with these terms. 